\title{
Anchovy (Engraulis encrasicolus) otoliths reveal growth differences between two areas of the Spanish Mediterranean Sea
}

\author{
Ana Ventero ${ }^{1}$, Magdalena Iglesias ${ }^{1}$, Begoña Villamor ${ }^{2}$ \\ ${ }^{1}$ Instituto Español de Oceanografía. Centre Oceanogràfic de Balears. Muelle de Poniente s/n. Apdo. 291, \\ 07015 Palma de Mallorca, Spain. \\ (AV) (Corresponding author) E-mail: aventero@ba.ieo.es. ORCID-iD: http://orcid.org/0000-0002-9906-3233 \\ (MI) E-mail: magdalena.iglesias@ba.ieo.es. ORCID-iD: http://orcid.org/0000-0002-9983-558X \\ ${ }^{2}$ Instituto Español de Oceanografía. Centro Oceanográfico de Santander. Promontorio San Martín, s/n. Apdo. 240, \\ 39080 Santander, Spain. \\ (BV) E-mail: begoña.villamor@st.ieo.es. ORCID-iD: http://orcid.org/0000-0002-4300-5771
}

\begin{abstract}
Summary: Anchovy is a commercial species that supports large fisheries in the Mediterranean Sea. In addition, anchovy is an essential element of the pelagic food web, playing a considerable role in connecting the lower and upper trophic levels. Comparisons made regarding length frequency distribution, demographic structure, growth during the first year inferred from otoliths, and the condition factor of anchovy inhabiting the Spanish Mediterranean Sea (General Fisheries Commission for the Mediterranean management units, GSA06-Ebro Delta and 01-Alboran Sea), based on five-year data, clearly showed significant growth differences between areas and evidenced the existence of two independent anchovy stocks in the Spanish Mediterranean Sea. The anchovies inhabiting the Alboran Sea had higher growth than the anchovies inhabiting the Ebro Delta for the same age (one year old). The dramatic decline of the Alboran Sea anchovy could be related to the current management legislation in the Spanish Mediterranean Sea, based mainly on a common minimum catch size $(9 \mathrm{~cm})$, which should be revised given that sustainable anchovy exploitation is crucial for the pelagic food web equilibrium.
\end{abstract}

Keywords: anchovy growth; length-frequency distribution; otolith first radius; anchovy stocks; condition factor; fisheries management; Spanish Mediterranean Sea.

Otolitos de anchoa (Engraulis encrasicolus) revelan diferencias de crecimiento entre dos áreas del Mediterráneo español

Resumen: La anchoa es una especie de interés comercial sometida a gran explotación pesquera en el mar Mediterráneo. Asimismo, esta especie es un elemento esencial de la cadena trófica pelágica dado que actúa como nexo entre los niveles más altos y más bajos de ésta. En este trabajo se han llevado a cabo comparaciones, basadas en un conjunto de datos de 5 años, entre las distribuciones de frecuencias de tallas; la estructura demográfica; el crecimiento durante el primer año, inferido empleando otolitos y el factor de condición de individuos de anchoa recogidos en el Mediterráneo español (unidades de gestión de la General Fisheries Commission for the Mediterranean, GSA06-Delta del Ebro y GSA01-Mar de Alborán), mostrando diferencias significativas entre áreas y evidenciando la existencia de dos stocks de anchoa independientes en el Mediterráneo español. Las anchoas procedentes del mar de Alborán presentaron un mayor crecimiento que aquellas procedentes del Delta de Ebro para la misma edad (1 año). La dramática disminución de la población de anchoa del mar de Alborán podría estar relacionada con la aplicación de una única legislación para todo el Mediterráneo español basada, principalmente, en una misma talla de primera captura $(9 \mathrm{~cm})$, que debería ser revisada puesto que la explotación sostenible de la anchoa es de crucial importancia para el equilibrio de la cadena trófica pelágica.

Palabras clave: crecimiento de anchoa; distribución de frecuencias de tallas; primer radio del otolito; stocks de anchoa; factor de condición; gestión de pesquerías; mar Mediterráneo español.

Citation/Como citar este artículo: Ventero A., Iglesias M., Villamor B. 2017. Anchovy (Engraulis encrasicolus) otoliths reveal growth differences between two areas of the Spanish Mediterranean Sea. Sci. Mar. 81(3): 327-337. doi: http://dx.doi.org/10.3989/scimar.04615.21A

Editor: V.M. Tuset.

Received: February 2, 2017. Accepted: April 27, 2017. Published: July 25, 2017.

Copyright: (9) 2017 CSIC. This is an open-access article distributed under the terms of the Creative Commons Attribution (CC-by) Spain 3.0 License. 


\section{INTRODUCTION}

Small pelagics such as anchovy support large fisheries in the Mediterranean Sea (Lleonart and Maynou 2003). Like other small pelagic species, the anchovy has a short life span, with high rates of natural mortality and fecundity in which recruitment plays a major role in setting year-to-year changes in the level of the stock (Fréon et al. 2005). Areas of high productivity generally influence the location of the spawning sites and spawning intensity, giving it a seasonal character. Sexual maturity occurs during the first year and only one or two cohorts significantly contribute to the fishery (Fréon et al. 2005). In the Spanish Mediterranean, anchovy spawning takes place from April to October, with a peak in June-July (Giráldez and Abad 1995, Palomera 1992).

Due to its high economic value, anchovy is the main target species of the purse seine fleet in the Spanish Mediterranean Sea, which covers two areas, GSA06 (northern Spain) and GSA01 (northern Alboran Sea), of the 30 stocks management areas established by the General Fisheries Commission for the Mediterranean (GFCM 2007). In the period 1990-2014, anchovy catches were highly variable, with an average of 12000 $\mathrm{t}$ in GSA06 and an average of $891 \mathrm{t}$ in GSA01. Whereas in GSA06 the anchovy catches are spread throughout the area (from the French border until the Cape of Palos), in GSA01 they are mainly located in the Bay of Málaga, the only area where anchovy is fished throughout the year (CFCM 2015).

Fishery-independent data provided by scientific surveys play an important role in the assessment and management of fish populations (Pennington and Stromme 1998). Research surveys are used to calibrate stock assessment models based on commercial catches (i.e. fishery-dependent data) and to provide empirical, independent population checks. (Kline 1996, Pennington and Stromme 1998). In order to determinate the anchovy spawning stock biomass, the small pelagic species assessment survey (MEDIAS) is carried out every summer by the countries within the European Union using acoustic methods. The assessment survey takes place during the anchovy spawning peak when mixing between putative stocks is minimal (Cadrin et al. 2014), so the MEDIAS survey period is optimal for discriminating between anchovy stocks.

Various methods of stock discrimination in marine fishes have been widely used, especially spawning areas and seasons, abundance and distribution patterns, length-frequency distribution differences (Guerra-Sierra and Sánchez-Lizaso 1998), tagging and migration studies, parasites, serology (Cadrin et al. 2014), biochemical-genetic differences (Zarraonaindia et al. 2012, Viñas et al. 2013) and otolith morphometric parameters (Cendrero and Abaunza 2001, Carvalho and Castello 2013, Jansen et al. 2013). Otolith length is an ideal measurement for determining anchovy length, because a quasi-perfect linear relationship exists between them (Zengin et al. 2015). Moreover, the length of the anchovy otolith first radius (R1) can be understood as an indicator of first-year growth (Hernández et al. 2013).
Otoliths, also called ear-bones, are part of the fish auditory system (Ladich and Schulz-Mirbach 2016). They are made mostly of calcium carbonate (Panfili et al. 2002), and as the fish grows, so does the otolith, by deposition of concentric layers of material according to a daily rhythm (Pannella 1971). Seasonal changes in the fish growth rate are reflected in the otolith. A year's growth consists of a wider summer zone, reflecting a faster growth rate related to higher food availability, and a narrower winter zone, reflecting a slower growth rate (Panfili et al. 2002). Therefore, due to their special characteristics, otoliths can be a useful tool for age determination (Rodriguez Mendoza 2006). Knowledge of the population age structure of an exploited fish species is the key to understanding its basic population biology and is a necessary prerequisite for providing effective advice to fisheries managers (Cadrin et al. 2014).

During the MEDIAS survey (2012-2016), larger anchovy individuals were always collected from GSA01 (Alboran Sea). Initially, it was thought that older anchovies inhabited this area, but the interpretation of the annual rings in otoliths gave the same age structure in both areas (GSA01 and GSA06). The main question to be resolved was: Are the observed differences in anchovy growth pattern due to the fact that the GSA01 and GSA06 subareas hold different anchovy stocks?

Taking the Spanish part of the Alboran Sea and the Ebro Delta as reference sites of GSA01 and GSA06 respectively, as they are the most productive areas of each GSA (Bellido et al. 2008), the hypothesis of the existence of different anchovy stocks along the Spanish Mediterranean Sea has been tested.

In order to test the null hypothesis: "anchovy inhabiting the Spanish Mediterranean constitute a single stock" different and complementary methodologies have been applied to the MEDIAS survey time series data (2012-2016): differences in length, based on the length frequency distribution; differences in growth, based on otolith reading and otolith morphometric parameters; and differences in the condition factor, based on the length-weigh relationship parameters.

The separation of stocks is of primary importance for the sustainable management of the fisheries and has important ecological consequences. The findings highlighted in this paper have great economic and ecological relevance because the management of the anchovy population in the Mediterranean Sea as two different stocks with different fishing regulations will reduce the pressure on GSA01 anchovies and will in the future achieve the recovery of the population.

\section{MATERIALS AND METHODS}

\section{Study area and fish sampling}

Samples were obtained from the western part of the Mediterranean Sea at two locations along the Spanish continental shelf: the Ebro Delta and the Alboran Sea (Fig. 1). The samples collected in the Ebro Delta area were considered as representative of the GSA06 (northern Spain) geographical subarea (GFCM 2007). Samples collected in the Spanish part of the Alboran 


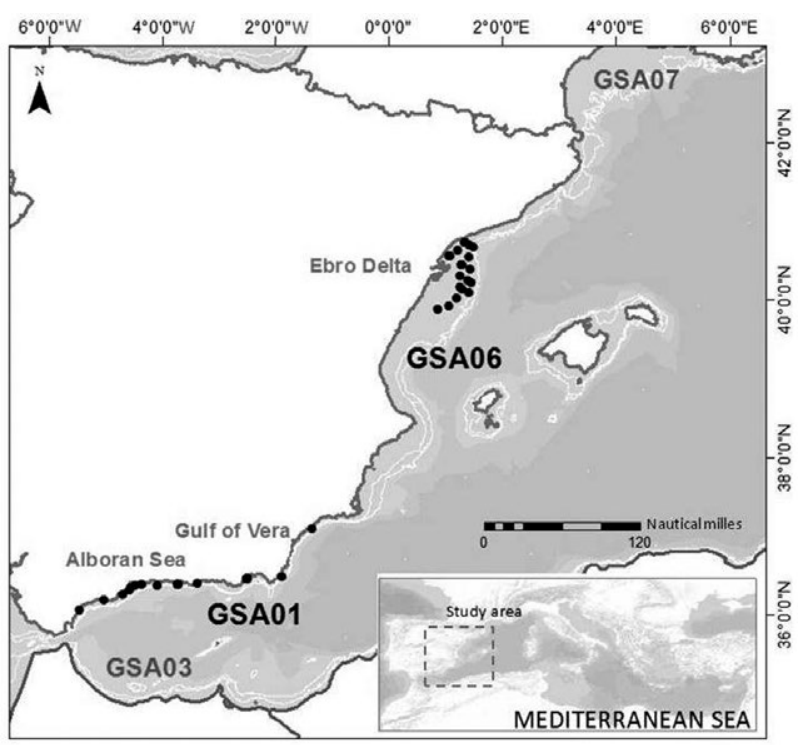

Fig. 1. - Study area. The Spanish Mediterranean Sea zoomed showing the sampling stations. General Fisheries Commission for the Mediterranean management units (GSAs) are included: in black the studied GSAs (GSA06, northern Spain, and GSA01, northern Alboran Sea) and in grey the adjacent GSAs (GSA07, Gulf of Lions, and GSA03, southern Alboran Sea). The white lines represent the isobaths between 100 and $200 \mathrm{~m}$, the deepest one being the continental shelf limit.

Sea and the Gulf of Vera were considered as representative of the GSA01 (northern Alboran Sea) geographical subarea (GFCM 2007).

Sampling was carried out during the 2012, 2013, 2014, 2015 and 2016 MEDIAS Spanish surveys. These monitoring surveys take place every year in June-July coinciding with the anchovy spawning peak, when the whole anchovy spawning population come together in order to maximize their reproductive success. For this reason, the samples obtained in both GSAs are expected to be representative of the whole population without bias (Table 1).

The sampling strategy adopted on the MEDIAS survey involves using a parallel transects design that covers the continental shelf from a depth of 30 to 200 $\mathrm{m}$. Transects are spaced according to the continental shelf width, four nautical miles (nm) in GSA01, where the continental shelf is very narrow ( $5 \mathrm{~nm}$ or less), and eight $\mathrm{nm}$ in GSA06, where the continental shelf is wider (20 nm or more). Acoustic data were recorded every nm using a calibrated EK60 (SIMRAD) scientific echosounder working with five split-beam transducers at 18, 38, 70, 120 and $200 \mathrm{kHz}$ frequencies, with a constant vessel speed of 10 knots $(\mathrm{nm} / \mathrm{h})$. Anchovy echotraces (fish schools) which were detected on the echogram were identified by "ground-truth" information (McClatchie et al. 2000) obtained by pelagic trawl net samples targeted at the echotraces (Simmonds et al. 1992).

\section{Length-frequency distribution and biological samples}

For each sampling event, a standard protocol was used: total catch was separated by species and anchovy individuals were randomly selected and measured to the nearest $0.5 \mathrm{~cm}$ in order to obtain the length-frequency distribution (LFD). A subsample of five individuals were selected for each 0.5 -cm length group for biological analysis, from which anchovy total length (TL, to the nearest $1 \mathrm{~mm}$ ), total wet weight (W, to the nearest $1 \mathrm{~g}$ ), sex and maturity stage (based on macroscopic observation of the gonads) were determined (ICES 2008). Finally, the sagitta otoliths were removed.

\section{Age determination}

The age of the anchovy was determined from the annual rings on the anchovy otoliths. The sagitta otoliths (1137 pairs; Table 1) were removed using the 'open-the-hatch method' described by Secor et al. (1992). After drying and cleaning, otoliths were placed on black plastic plates and mounted on transparent non-plastic resin. Otolith pairs were positioned with the sulcus facing downwards and were examined under a binocular stereoscope; the magnification used was between 20 and $40 \times$ depending on the otolith size (ICES 2009, Villamor et al. 2014). The anchovies were aged following the standards established for this species in ICES (ICES 2009), with the date of birth taken arbitrarily as 1 July. For each otolith, the number of true hyaline rings (excluding the edge), edge type, assigned age and readability ( 0 , good; 1 , medium; 2, difficult), as well as false rings (checks), were recorded. Typical checks occur before and after the formation of the first winter ring in anchovy of ages 0 and 1 (Hernández et al. 2013, ICES 2013, Uriarte et al. 2016). The otoliths were read twice by the same reader (firstly, without knowing the length and, secondly, taking into account all the biological variables sampled, such as length, sex and maturity). A set of 250 otoliths was used to validate the readings by a second expert reader. Otolith reading was considered accurate as the degree of agreement between readers was $87 \%$.

Table 1. - Periods of survey, sample locations (GSA06/GSA01), anchovy individuals measured to the nearest $0.5 \mathrm{~cm}$, otolith pairs extracted and read and otolith R1 measured.

\begin{tabular}{|c|c|c|c|c|c|c|c|}
\hline \multirow[b]{2}{*}{ Survey acronym } & \multirow[b]{2}{*}{ Date } & \multicolumn{2}{|c|}{ Individuals measured } & \multicolumn{2}{|c|}{ Otolith pairs extracted } & \multicolumn{2}{|c|}{ Otolith R1 measured } \\
\hline & & GSA06 & GSA01 & GSA06 & GSA01 & GSA06 & GSA01 \\
\hline MEDIAS 2012 & 13 June-12 July & 565 & 361 & 82 & 60 & 74 & 60 \\
\hline MEDIAS 2013 & 29 June-31 July & 490 & 112 & 41 & 49 & 31 & 49 \\
\hline MEDIAS 2014 & 20 June-22 July & 655 & 220 & 168 & 64 & 138 & 64 \\
\hline MEDIAS 2015 & 23 June-25 July & 780 & 642 & 130 & 146 & 110 & 114 \\
\hline MEDIAS 2016 & 24 June26 July & 830 & 782 & 188 & 209 & 141 & 193 \\
\hline Total by GSA & & 3320 & 2117 & 609 & 528 & 494 & 480 \\
\hline Total & & \multicolumn{2}{|c|}{5437} & \multicolumn{2}{|c|}{1137} & \multicolumn{2}{|c|}{974} \\
\hline
\end{tabular}




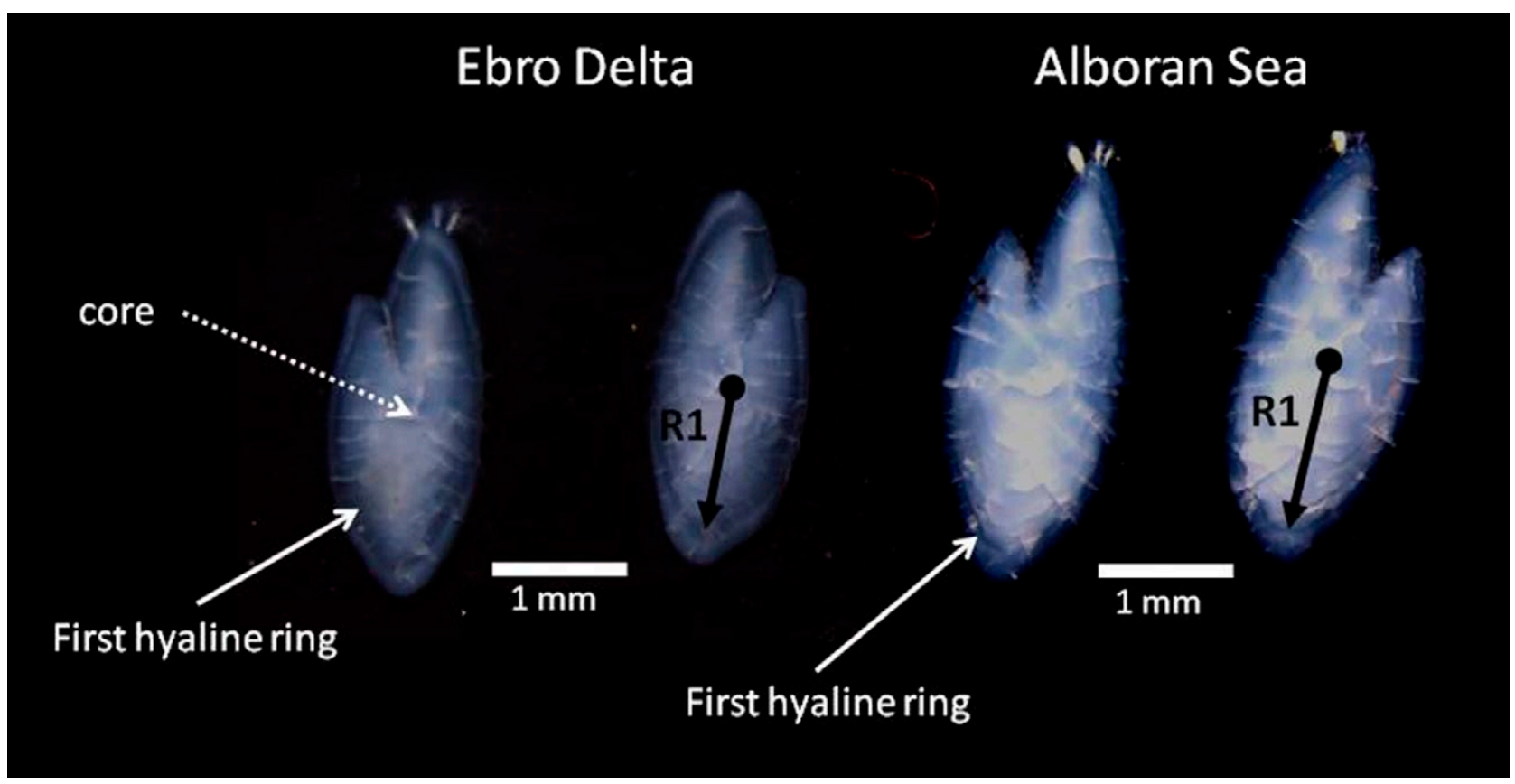

Fig. 2. - Typical morphology of anchovy otolith pairs found in GSA06 (Delta Ebro) and GSA01 (Alboran Sea), indicating the first hyaline ring and how the otolith first radio (R1) was measured.

First year growth estimation (R1)

In order to test the hypothesis of different anchovy growth rates between GSAs, the first year anchovy growth was estimated by measuring the first annual ring radius (R1) on otolith digitized photographs (Fig. 2). R1 was defined as the distance in microns between the core (the initial complex structure of an otolith) and the inner edge of the first hyaline ring. R1 was measured across the widest part of the otolith, along the same axis used to estimate the age of the fish (Fig. 2). A total of 974 otoliths pairs corresponding to 1- or 2-year-old anchovy (Table 1) were digitized using an image analysis system consisting of a calibrated high-resolution MOTIC camera (Moticam 5) connected to an optical microscope (Leica EZ4). The digitized image was then analysed using image analysis software (Motic Images Plus 2.0).

\section{Condition factor}

In order to investigate whether the specific environmental characteristics of each GSA influence the relative robustness or degree of well-being of anchovy individuals, the anomaly in weight of a given length was determined by means of a condition factor index. As anchovy exhibited an allometric growth pattern for the five years studied (Table 3 ), the relative condition factor index Kn (Le Cren 1951) was used as a proxy of individual fish condition (Green 2001, Froese 2006). Indeed, using $\mathrm{Kn}$ as the index to calculate the condition factor, the potential effect of length is avoided as well as allowing for cross-population comparisons. The Kn index is computed as:

$$
\mathrm{Kn}=\mathrm{W} / \mathrm{Wr}
$$

where $\mathrm{W}$ is the weight of an individual and $\mathrm{Wr}$ is the theoretical weight of an individual of a given TL (in $\mathrm{mm}$ ). This theoretical weight was estimated by a length-weight relationship $\left(\mathrm{Wr}=\mathrm{a} \mathrm{TL}^{\mathrm{b}}\right.$ ), employing the geometric mean of the regression parameters "a" and "b" across the 5437 individual measured (from 2012 to 2016), as Froese (2006) recommended for population comparison. Immediately afterwards, the condition factor was computed by sex separately and GSA (GSA01 and GSA06). In addition, the length-weight regression parameters were calculated by year, GSA and sex. Finally the sex ratio (males/females) was computed for every year.

\section{Statistical analyses}

The differences in length observed during the sampling routine in the Spanish Mediterranean Sea were tested applying the Kolmogorov-Smirnov test to the GSA LFD data by year.

R1 measures were tested for normality (Shapiro test) and homogeneity of variance (Levene test). As the normality and homogeneity of variance hypotheses could not be assumed, the possible intra- (same GSA) and inter-area (GSA06 and GSA01) differences between years were checked using non-parametric statistical techniques, a Kruskal-Wallis test followed by the Tukey and Kramer (Nemenyi) post hoc test, in order to find out which pairwise combinations of samples were significantly different. The major trends in R1 were analysed by means of a non-metric multidimensional scaling (nMDS) and a cluster analysis. Similarity matrices were constructed based on BrayCurtis similarity with the square-root-transformed biometric variables: length, weight and R1. nMDS assigns a non-dimensional location to each group and 
2012

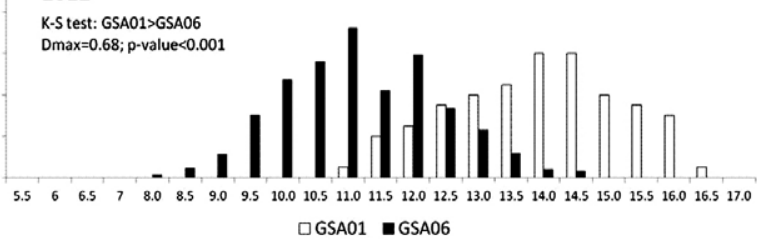

25013

20. K-S test: GSA01>GSA06

15. Dmax $=0.95 ; p$-value $<0.001$

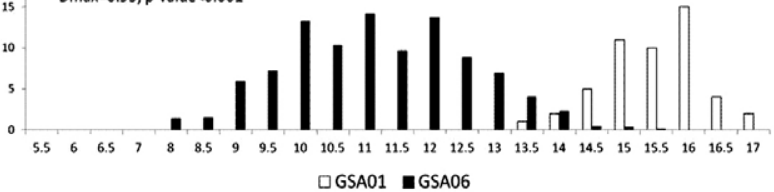

$\square$ GSA01 @GSA06
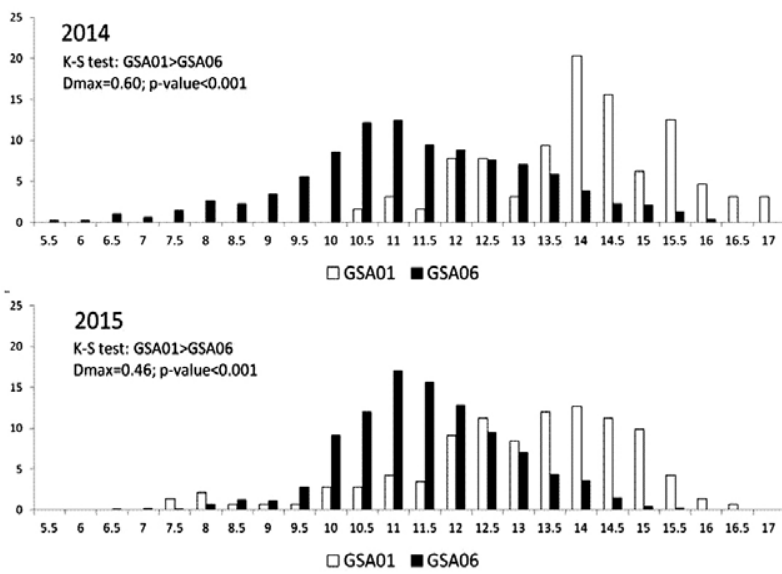

2016

20 - K-S test: GSA01>GSA06

D $\max =0.70 ;$ p -value $<0.001$

10.

5

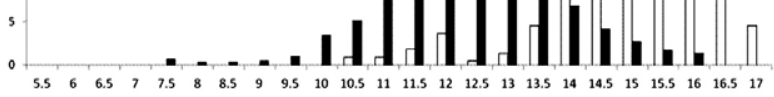

GSA01 -GSA06

Fig. 3. - Anchovy length (to the nearest $0.5 \mathrm{~cm}$ ) frequency distribution in percentage of individuals for each GSA and year; in black GSA06 data and in white GSA01 data. The figure also shows the results of the Kolmogorov-Smirnov (K-S) test used to compare anchovy length distributions between GSAs: GSA01>GSA06 represent the null hypothesis "anchovies collected in GSA01 had a greater length than those collected in GSA06", the maximum difference between the two probability distributions (Dmax) and the p-value.

calculates the distance between groups. A non-dimensional plot is based on those distances, reflecting the similarities between groups, so similar groups are plotted closer to each other and dissimilar groups are further apart. Statistical tests were carried out using R version 3.2.2 (R Development Core Team 2015) and similarity analysis using PRIMER version 6 (Clarke and Gorley 2006).

The length-weight regression coefficients were compared between males and females by GSA using an ANOVA test to check whether significant differences occurred between sexes. In addition, the comparison between GSAs by sexes and for the whole population (ANOVA) was carried out to detect any inter-area differences.

\section{RESULTS}

\section{Length-frequency distribution}

A total of 5437 anchovy were measured to the nearest $0.5 \mathrm{~cm}$ (Table 1), Figure 3 shows the graphical representation of anchovy LFD by year for each management area, in black GSA06 and in white GSA01. For every year and GSA, anchovy length distribution was unimodal; the modal value (the value that appears most in the dataset) was $11.0 \mathrm{~cm}$ for all the years in GSA06 and $14.0 \mathrm{~cm}$ for 2012, $16.0 \mathrm{~cm}$ for $2013,14.0$ $\mathrm{cm}$ for $2014,14.0 \mathrm{~cm}$ for 2015 and $15.0 \mathrm{~cm}$ for 2016 in GSA01. Although there was a certain degree of overlap, anchovies caught in GSA06 had a smaller modal and mean length than anchovies caught in GSA01. The differences observed in the graphical representation were confirmed using a Kolmogorov-Smirnov test (Fig. 3). Kolmogorov-Smirnov test results revealed firstly that the null hypothesis "anchovies collected in GSA01 had a greater length than those collected in GSA06 (GSA01>GSA06)" was fulfilled for every year ( $<<0.001$ in any case), and secondly that the maximum difference between the two probability distributions (Dmax) was recorded in 2013 (Dmax=0.95), indicating that the overlap between distributions was minimal, while the maximum overlap was recorded in 2015 $(\mathrm{Dmax}=0.46)$.

\section{Age determination}

A total of 1137 otolith were read (Table 1) and the age frequency distribution by year and GSA is shown in Figure 4. The age determination process revealed that most of the anchovies belonged to age-1, regardless of the GSA. In GSA06 (Fig. 4, in black) the age structure was similar for all five years. It was based on three annual classes $(0,1$ and 2 years), the one-yearold individuals being the most abundant ones (more than $75 \%$ of individuals). In GSA01 (Fig. 4, in white), for the years 2012, 2013 and 2014 only one-year-old anchovy were found, whereas for the years 2015 and 2016 recruits (age 0) and two-year-old anchovies were present in the area, although to a lesser degree (5-10\% of individuals). Although anchovy in GSA01 exhibited a greater length than in GSA06 (Fig. 3) the age structure was found to be similar, based on only three annual classes, or fewer in the case of GSA01 (Fig. 4).

\section{First year growth estimation (R1)}

A total of 974 otoliths were analysed (Table 1). The first annual ring radius (R1) was measured in every otolith as an indicator of the anchovy growth rate during the first year. All the one- or two-year-old anchovy are represented in the R1 samples since they have developed the first hyaline radius. R1 density functions for each GSA and for the total dataset (Fig. 5) were tested for normality and homogeneity of variance. The normality assumption, carried out using the Shapiro test, could not be assumed either for the total data $(\mathrm{p}<0.001)$ or for any of the GSAs $\left(\mathrm{p}_{\mathrm{GSA} 06}<0.001\right.$ 

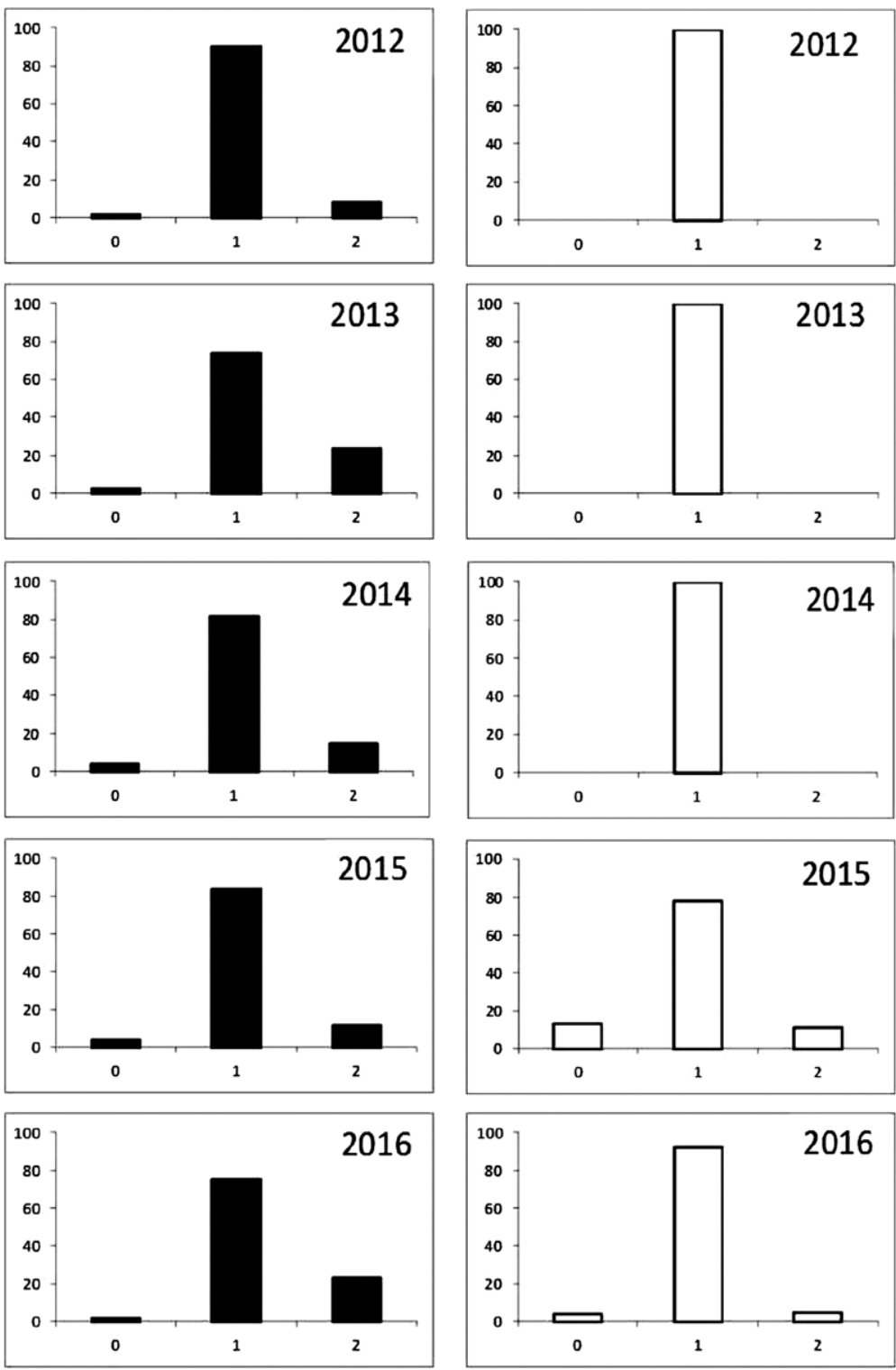

Fig. 4. - Anchovy age distribution (percentage) by year group (years) for the time series in GSA06 on the left side (in black) and GSA01 on the right side (in white).

and $\left.\mathrm{p}_{\mathrm{GSA} 01}<0.001\right)$. As a result of the Levene test, the hypothesis of homogeneity of variances could not be accepted for the total $(\mathrm{F}=12.14 ; \mathrm{df}=9$ : $\mathrm{p}<0.001)$, for GSA06 $(\mathrm{F}=21.15 ; \mathrm{df}=4 ; \mathrm{p}<0.001)$ or for $\mathrm{GSA} 01$ $(\mathrm{F}=4.47 ; \mathrm{df}=4 ; \mathrm{p}<0.001)$.

The differences observed in the graphical representation of the R1 frequency distribution between GSAs by year (Fig. 6) were confirmed by the results of the non-parametric Kruskal-Wallis test (chisquared $=985.85, \mathrm{df}=871, \mathrm{p}<0.05$ ), so the medians were not equal in GSA01 and GSA06.

The pairwise comparisons using a Tukey and Kramer (Nemenyi) post hoc test with Tukey distance approximation for independent samples (Table 2) revealed that for all possible combinations between years and GSAs, the differences in R1 between GSA01 and

Table 2. - Tukey and Kramer (Nemenyi) post hoc test results.

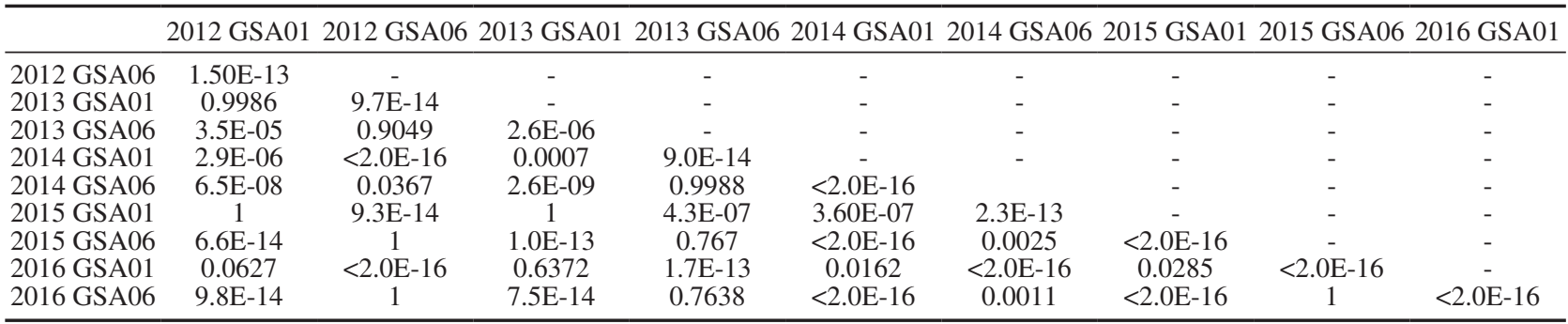



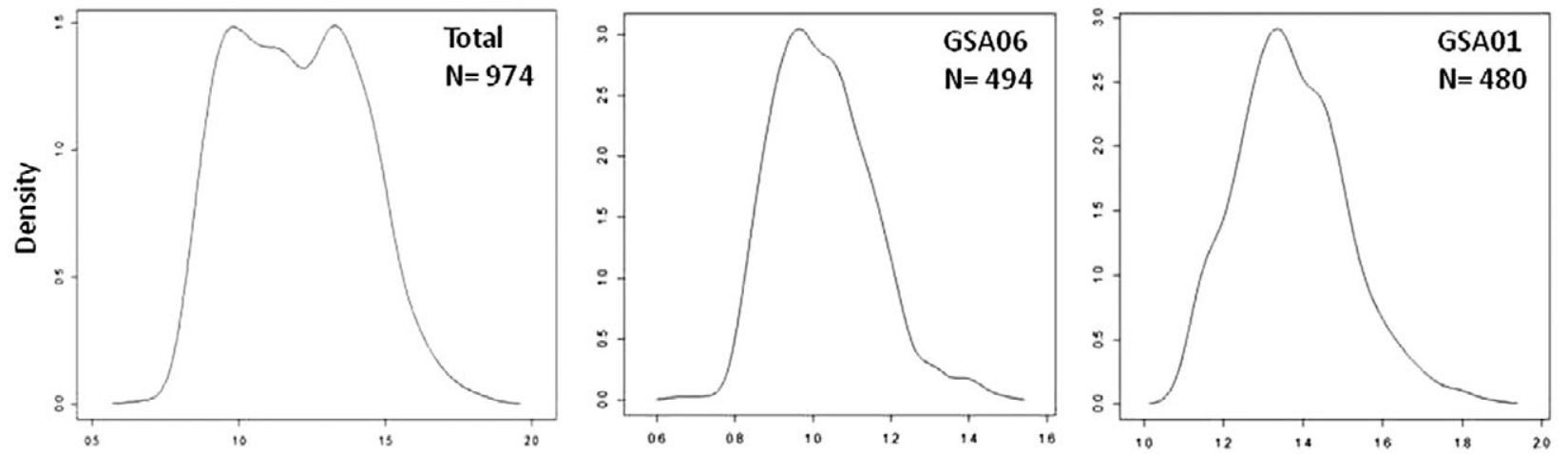

Fig. 5. - First otolith radio (R1) density functions, including the number of measured individual (N), both total and by GSA.

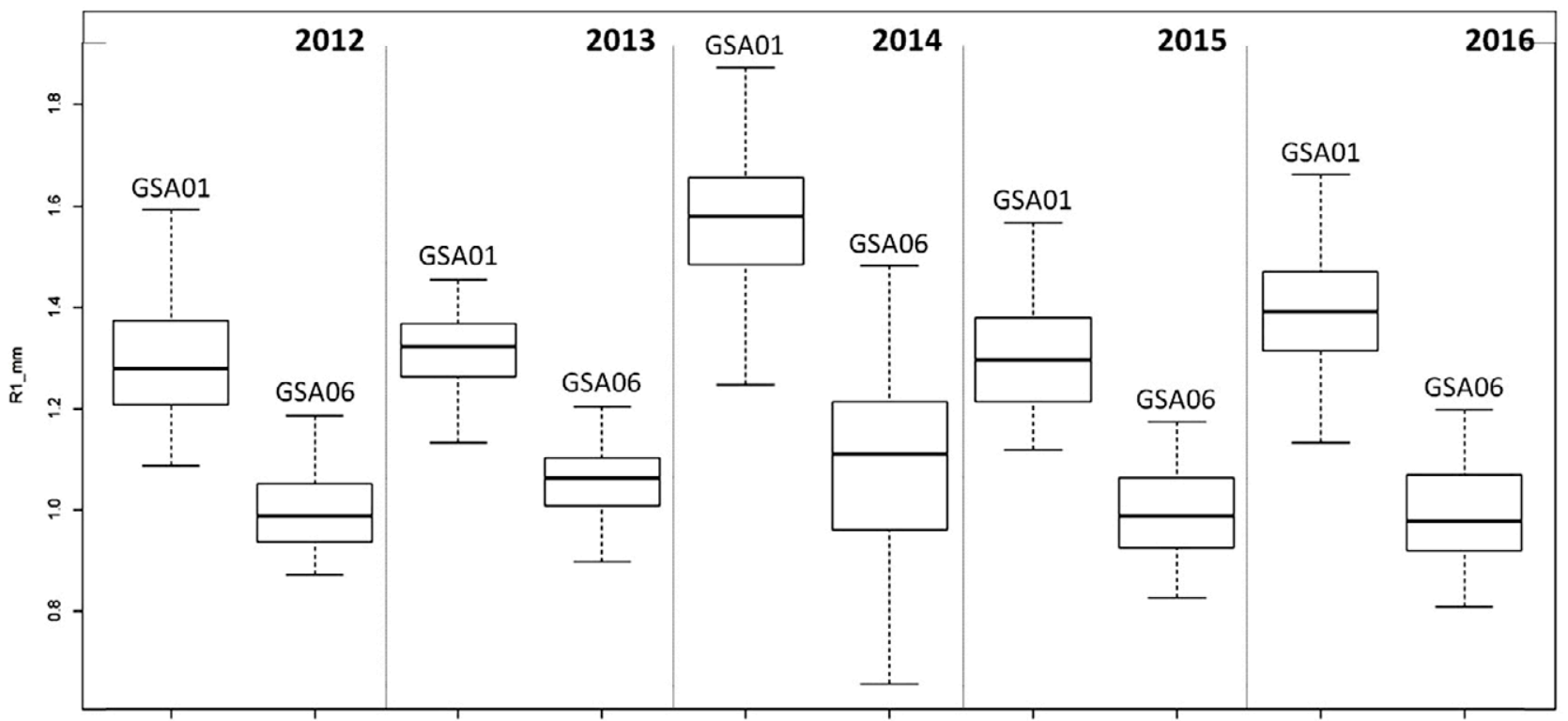

Fig. 6. - Box plot showing the first otolith radius (R1) length (mm) distribution per year and GSA. The mid-point of the data (median) is shown by the line that divides the box into two parts; the middle "box", limited by the first quartile (Q1) and the third quartile (Q3), represents the interquartile range (IQR), and the upper and lower whiskers represent the Q1-1.5*IQR and the Q3-1.5*IQR respectively.

GSA06 were statistically significant $(\mathrm{p}<0.001$; Table 2). The null hypothesis could not be accepted, so anchovies in GSA06 and GSA01 came from different anchovy stocks. Moreover, inter-annual differences were found within the same GSA: for GSA01 the pair of years 2012-2014, 2013-2014, 2014-2015, 20142016 and 2015-2016 were significantly different and for GSA06 the pair of years 2012-2014, 2014-2015 and 2014-2016 were also significantly different $(\mathrm{p}<0.05$; Table 2).

Most of the patterns observed in the non-parametric analysis (Table 2) were validated by the nMDS (Fig. 7A) and cluster analysis (Fig. 7B) using the length, weight and R1. GSA06 and GSA01 data appeared to be separated by a significant distance in the nMDS plot, indicating two well-defined stocks.

\section{Condition factor}

The length-weight relationship computed for all the data pooled based on a five-year dataset including more than 5000 individuals (Table 1) was characterized by a
$=0.0035$ and $b=3.21\left(R^{2}>0.95, p<0.001\right)$. The coefficients "a" and "b" obtained from the regression analysis for each GSA by sexes for every year studied are given in Table 3, as is the sex-ratio. The variation in the allometric parameter " $b$ " suggests inter-annual changes in the population's mean weight within the two GSAs, with the highest weight values in 2012 in GSA01 and in 2013 in GSA06. The parameter "b" was greater than 3 (positive allometric) in most of the cases, indicating that anchovy growth is greater in weight than in length in both GSAs. At 0.05 significance level, the ANOVA test showed no significant differences between sexes for the same GSA. In GSA01, the differences in " $a$ " $(\mathrm{F}=0.026 ; \mathrm{df}=4 ; \mathrm{p}<0.05)$ and "b" $(\mathrm{F}=0.068 ; \mathrm{df}=4$; $\mathrm{p}<0.05)$ between males and females were not significant. In GSA06 the same result was obtained: the differences in "a" $(\mathrm{F}=0.042 ; \mathrm{df}=4 ; \mathrm{p}<0.05)$ and "b" $(\mathrm{F}=0.079 ; \mathrm{df}=4 ; \mathrm{p}<0.05)$ between males and females were not significant. In both cases the null hypothesis of equality was accepted. The opposite result was obtained when males and females from different GSAs were compared, but only for the "b" regression param- 

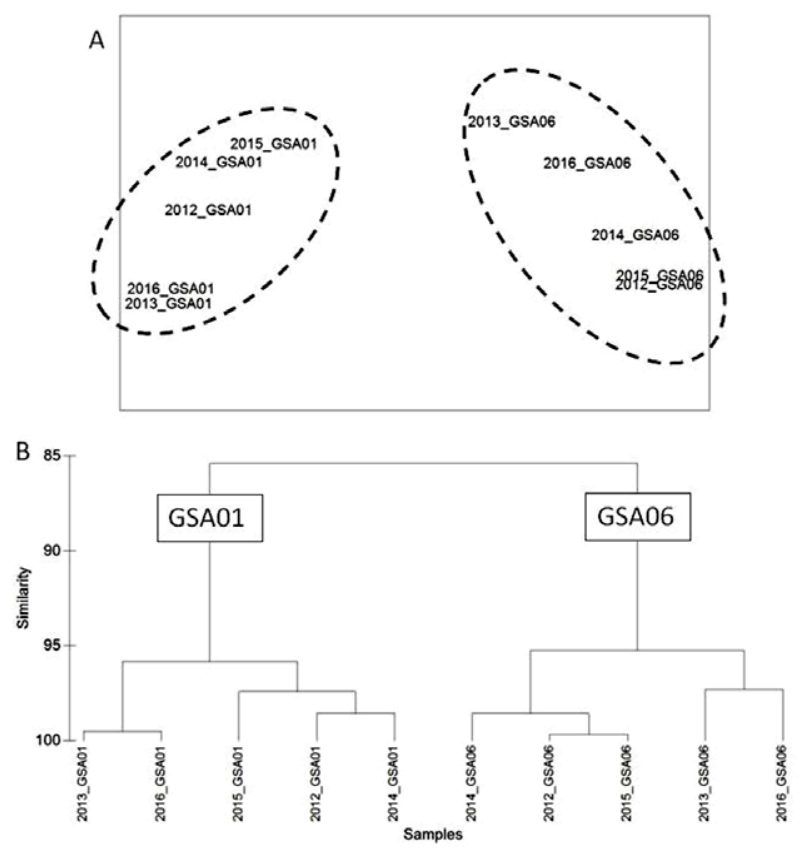

Fig. 7. - A, nMDS results and B, cluster analysis output depicting the linkage dendrogram (Bray-Curtis similarity) computed on length, weight and R1 for the five years and GSAs (stress: 0.02). The superimposed ellipses in A represent the two different groups detected, which correspond to the GSA06 and GSA01 anchovy stocks. The two main branches in B split the GSA01 and GSA06 data, indicating two different anchovy groups.

eter. In the case of males, $F$ was $5.725(\mathrm{df}=4 ; \mathrm{p}<0.05)$, in the case of females, $F$ was $8.721(\mathrm{df}=4 ; \mathrm{p}<0.05)$ and for the total population, $F$ was $6.292(\mathrm{df}=4$; $\mathrm{p}<0.05)$. Therefore, the increment in weight relative to length was more pronounced in GSA01 than in GSA06 for both males and females.

The condition factor index $(\mathrm{Kn})$ remained practically constant from 2012 to 2016 in both areas for males and females (Fig. 8), although in all cases the Kn showed a higher value in GSA01 than in GSA06. For the same GSA the Kn values reached by males were almost equal to the values reached by females, except in GSA01 in 2012, where females showed a higher Kn than males. The healthier state of anchovy in GSA01 than in GSA06 was reflected in the population

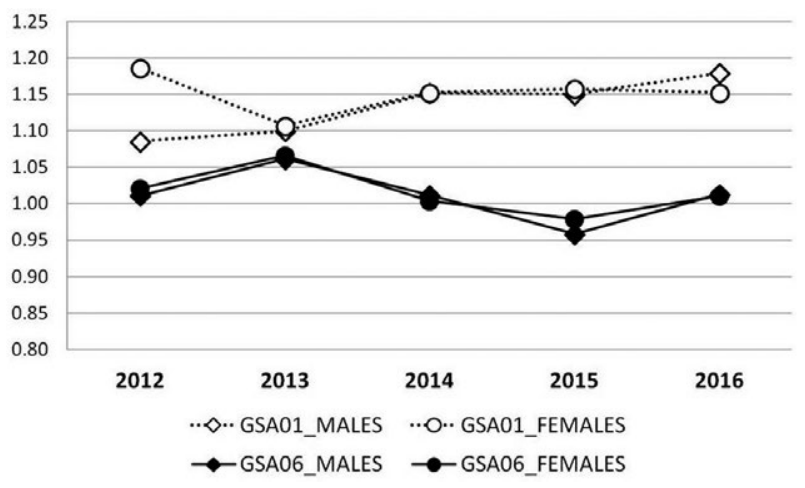

Fig. 8. - Time series of the annual anchovy body condition by sexes. The dotted line represents GSA01 and the continuous line represents GSA06. Males are symbolized by diamonds and females by circles.
Table 3. - Time series values of the regression coefficients ("a" and "b") of the length-weight relationships by GSA, year and sex, and the sex ratio (males/females) by year.

\begin{tabular}{lccrrrrr}
\hline GSA & Sex & $\begin{array}{c}\text { Regression } \\
\text { coefficients }\end{array}$ & 2012 & 2013 & 2014 & 2015 & 2016 \\
\hline GSA01 & Males & $\mathrm{a}$ & 0.002 & 0.008 & 0.002 & 0.004 & 0.005 \\
& & $\mathrm{~b}$ & 3.385 & 3.159 & 3.597 & 3.423 & 3.112 \\
& Females & $\mathrm{a}$ & 0.002 & 0.004 & 0.002 & 0.004 & 0.008 \\
& & $\mathrm{~b}$ & 3.501 & 3.285 & 3.463 & 3.398 & 3.268 \\
& Total & $\mathrm{a}$ & 0.001 & 0.003 & 0.002 & 0.005 & 0.007 \\
& & $\mathrm{~b}$ & 3.614 & 3.290 & 3.477 & 3.268 & 3.196 \\
& Sex-ratio & & 0.7 & 1.1 & 1.3 & 1.1 & 0.7 \\
GSA06 & Males & $\mathrm{a}$ & 0.004 & 0.003 & 0.004 & 0.005 & 0.003 \\
& & $\mathrm{~b}$ & 3.183 & 3.177 & 3.177 & 3.069 & 3.262 \\
& Females & $\mathrm{a}$ & 0.003 & 0.003 & 0.004 & 0.004 & 0.003 \\
& & $\mathrm{~b}$ & 3.206 & 3.207 & 3.161 & 3.165 & 3.339 \\
& Total & $\mathrm{a}$ & 0.004 & 0.003 & 0.004 & 0.006 & 0.004 \\
& & $\mathrm{~b}$ & 3.196 & 3.285 & 3.158 & 2.996 & 3.126 \\
& Sex-ratio & & 1.0 & 0.9 & 1.5 & 0.9 & 1.0 \\
\hline
\end{tabular}

demographic structure (Fig. 3), as well as in the condition factor index (Fig. 8) which was always greater in GSA01.

\section{DISCUSSION}

Research surveys constitute the main fisheriesindependent data source and contribute to the assessment and management of fish populations (Pennington and Stromme 1998). This study is based on data collected during the MEDIAS survey, which is of added value given that (1) the data lack spatial bias because the whole anchovy distribution area is covered and not only the fishing grounds; (2) catches are not restricted by depth or mesh size, so the entire population length range is sampled; (3) fisheries acoustics is a direct method based on "ground-truth" information, through which all the anchovy echotraces are identified (McClatchie et al. 2000); and (4) the survey period coincides with the anchovy spawning peak (Giráldez and Abad 1995, Palomera 1992) and with the maximum anchovy abundance (Palomera and Sabatés 1990), so it is optimal for stock discrimination (Cadrin et al. 2014).

The results of the current study point to the existence of two separate anchovy stocks in the Spanish Mediterranean Sea (GSA06 and GSA01), based on their different growth rates. Similar results have been reported in genetic studies (Sanz et al. 2008, Zarraonaindia et al. 2012, Viñas et al. 2013) and in studies on larval growth (Quintanilla et al. 2015). Moreover, similar differences in growth by area have also been observed for sardine (Sardina pilchardus) in the Spanish Mediterranean Sea (Alemany and Álvarez 1993).

LFDs exhibited clear differences between GSA06 and GSA01, GSA01 anchovy being larger than GSA06 anchovy. But, contrary to what could be expected, GSA01 anchovy were not older than GSA06 anchovy. This was the first evidence that these anchovy might not belong to the same population. The anchovy demographic structure found in the whole Spanish Mediterranean Sea was based chiefly on two year classes (anchovy of 0 and 1 year old), given that two-year-old anchovy were very scarce in GSA06 and almost absent in GSA01. Our results are in agreement with the fisheries-dependent data collected throughout the year 
(GFCM 2014, 2015), which confirm the MEDIAS survey data as an excellent benchmark. Moreover, a similar anchovy demographic structure for the same time period was found in the adjacent GSAs, GSA07, Gulf of Lions (Van Beveren et al. 2014) and GSA03, southern Alboran Sea (Bacha et al. 2010, 2014, Jemaa et al. 2015). Other studies carried out in earlier years in the Mediterranean Sea reported a life expectancy of 3 to 4 years (Basilone et al. 2004, Van Beveren et al. 2014) and 5 years in the Bay of Biscay (Uriarte et al. 1996), but all concluded that only a minor fraction belongs to these oldest age classes.

Small pelagic fish are essential elements of marine ecosystems due to their significant biomass at intermediate levels of the food web, playing a considerable role in connecting the lower and upper trophic levels (Cury et al. 2000). Anchovy plays an important part in the pelagic food web in the Spanish Mediterranean for primary producers and consumers as they constitute their prey (Costalago et al. 2012), as well as for higher trophic levels, such as anchovy predators (Cardona et al. 2015). Therefore, fluctuations in small pelagic populations due to fishing or natural factors modify ecosystem structure and functioning and have a major impact on the whole ecosystem (Cury et al. 2000).

In the Mediterranean Sea the anchovy exploitation rate has been steadily increasing since 1990, with the consequence that the demographic structure of the stocks has shrunk (Vasilakopoulos et al. 2014) and the anchovy life span has decreased (GFCM 2014). In fact, anchovy life expectancy has gone down in the last few decades in the Spanish Mediterranean Sea. During studies carried out in the 1980s four-year-old anchovy were commonly found (Pertierra 1987, Morales-Nin and Pertierra 1990), whereas now, using the same ageing criteria, adopting 1 July as the arbitrary birth dates, the oldest age found is two years old.

Interpreting the otolith's annual rings in order to age the anchovy is often a difficult task, especially given the presence of false rings and the difficulty of determining the edge type (ICES 2009, 2013). In the Spanish Mediterranean Sea two obvious distinctive otolith structures that matched the two study areas were observed during the reading process. In general, GSA01 otoliths were harder, with the anterior and posterior margin sharper, and showed less structural variability than the GSA06 otoliths, perhaps due to fewer cohorts contributing to the population in GSA01. In both areas otoliths showed a homogeneous, white, well-defined nucleus, being greater and more opaque in GSA01. GSA06 otoliths usually showed a small hyaline round area in the centre associated with the juvenile period, while in GSA01 this area was uncommon. This homogeneous nucleus was surrounded by a clear and continuous hyaline ring that corresponded to the first hyaline ring. The larger opaque centre observed in GSA01 otoliths was due to a higher anchovy growth rate during the first year, as confirmed by the R1 measures. This fact was the definitive proof of the existence of two anchovy stocks in the Spanish Mediterranean Sea, as was later corroborated by the results of the cluster analysis. The study of the degree of well-being of the anchovy population based on the condition factor index $(\mathrm{Kn})$ proposed by Le Cren (1951) revealed that anchovy individuals in GSA01 were not only larger in length, but also had a greater weight for a given length than the anchovy in GSA06. Both the Ebro Delta (GSA06) and the Alboran Sea (GSA01) are essential habitats for anchovy due to their productive conditions (Bellido et al. 2008). However, the enrichment process differs: in the Alboran Sea nutrient enrichment comes mainly from coastal upwelling (Agostini and Bakun 2002, Mercado et al. 2013), whereas in the Ebro Delta area it comes via the transport of nutrients from the Gulf of Lions and the turbulent mixture occurs as a result of the discharge of nutrient-rich fresh water coming from the Ebro River (Salat 1996, Agostini and Bakun 2002). The Atlantic water enters the Mediterranean through the Strait of Gibraltar. The inflow of the Atlantic water is first directed northeastward due to the orientation of the Strait of Gibraltar, and then generally describes a clockwise gyre in the east of the Alboran Sea between Spain and Morocco. This surface flow then spreads to the African coast, mainly due to the effect of the Coriolis force (El-Geziry and Bryden 2010). The surface circulation in northern Spain (GSA06) is dominated by two well-defined, density-driven currents. In the northern part, a frontal jet flows southwestward along the slope (Castellón et al. 1990). In the south, off the Gulf of Valencia, part of the flow continues its path southward along the Spanish coast. Another branch bifurcates and recirculates cyclonically to feed the return Balearic Current along the northern Balearic Island shelf (Pinot et al. 2002).

Though both areas are productive (Bellido et al. 2008), the chlorophyll and primary production values in the Alboran Sea are higher than those in the Delta zone (Siokou-Frangou et al. 2010, Lazzari et al. 2012, Salgado and Lorenzo 2014). By contrast, the surface temperature is lower in Alboran Sea than in the Ebro Delta area, although the main trend in both areas is an increasing temperature (Shaltout and Omstedt 2014) . Therefore, it can be deduced that the environmental variables are more favourable for anchovy in GSA01. Indeed, anchovy belonging to GSA01 show better condition than those from other Mediterranean or Black Sea areas, possibly because of the influence of the Atlantic Ocean (Brosset et al. 2017).

Though the GSA management areas established by the GFCM were based on political and statistical considerations rather than on biological or economic factors (Lleonart and Maynou 2003), they are indeed appropriate for anchovy management purposes in the Spanish Mediterranean Sea, so GSA01 and GSA06 should be maintained as individual areas for assessment, as also happened with demersal stocks in GSA05 (Balearic Islands) and GSA06 (Quetglas et al. 2012).

The results obtained in this study not only have a great biological relevance in verifying the existence of different anchovy stocks in the Spanish Mediterranean, but can also have a direct application in the fields of conservation and management. Anchovy belonging to GSA01 had a greater length at the same age and were in better condition than anchovy belonging to GSA06, 
but the unresolved question is: Why is the anchovy biomass per area in GSA01 lower than that in GSA06? (GFCM 2015). Perhaps this fact is related to the application of the same regulation concerning minimum legal length, $9 \mathrm{~cm}$ (BOE 1995), for the whole Spanish Mediterranean, which could negatively affect the anchovy GSA01 population. This aspect is paramount, because anchovy is a key component of the pelagic ecosystem (Cury et al. 2000) and its conservation is crucial for the pelagic food web equilibrium. Therefore, the decline of the anchovy population in the Alboran Sea could affect other species very negatively, destabilizing the food chain. Finally, the application of different legislation for these two zones is proposed, as other authors have also suggested (Pla et al. 1996, Lleonart and Maynou 2003, Viñas et al. 2013).

\section{ACKNOWLEDGEMENTS}

We are grateful to the fishing team that participated in the MEDIAS surveys, and especially to M.J. Melendez (IEO Málaga) and E. Herrera (IEO Murcia) for the extraction and preservation of otoliths. We would also like to thank the coastal pelagic resources assessment group from the IEO (Santander) for the otolith interchange exercises and for the support provided.

\section{REFERENCES}

Agostini V.N., Bakun A. 2002. 'Ocean triads' in the Mediterranean Sea: physical mechanisms potentially structuring reproductive habitat suitability (with example application to European anchovy, Engraulis encrasicolus). Fish. Oceanogr. 11: 129-142. https://doi.org/10.1046/j.1365-2419.2002.00201.x

Alemany F., Álvarez F. 1993. Growth differences among sardine (Sardina pilchardus Walb.) populations in Western Mediterranean. Sci. Mar. 57: 229-234.

Bacha M., Moali A., Benmansour N.E., et al. 2010. Relationships between age, growth, diet and environmental parameters for anchovy (Engraulis encrasicolus L.) in the Bay of Bénisaf (SW Mediterranean, west Algerian coast). Cybium 34: 47-57.

Bacha M., Jemaa S., Hamitouche A., et al. 2014. Population structure of the European anchovy, Engraulis encrasicolus, in the SW Mediterranean Sea, and the Atlantic Ocean: evidence from otolith shape analysis. ICES J. Mar. Sci. 71: 2429-2435. https://doi.org/10.1093/icesjms/fsu097

Basilone G., Guisande C., Patti B., et al. 2004. Linking habitat conditions and growth in the European anchovy (Engraulis encrasicolus). Fish. Res. 68: 9-19. https://doi.org/10.1016/j.fishres.2004.02.012

Bellido J.M., Brown A.M., Graham J.P., et al. 2008. Identifying essential fish habitat for small pelagic species in Spanish Mediterranean waters. Hydrobiologia 612: 171-184 https://doi.org/10.1007/s10750-008-9481-2

BOE. 1995. Real Decreto 560/1995, de 7 de abril, por el que se establecen las tallas mínimas de determinadas especies pesqueras. BOE 84: 10552-10554

Brosset P., Fromentin J.M., Van Beveren E., et al. 2017. Spatiotemporal patterns and environmental controls of small pelagic fish body condition from contrasted Mediterranean areas. Progr. Oceanogr. 151: 149-162. https://doi.org/10.1016/j.pocean.2016.12.002

Cadrin S.X., Kerr L.A., Mariani S. 2014. Stock identification methods: application in fisheries science. 2nd ed. Elsevier, Amsterdam, $566 \mathrm{pp}$. https://doi.org/10.1016/b978-0-12-397003-9.00001-1

Cardona L., Martínez-Iñigo L., Mateo R., et al. 2015. The role of sardine as prey for pelagic predators in the western Mediterranean Sea assessed using stable isotopes and fatty acids. Mar. Ecol. Prog. Ser. 531: 1-14

https://doi.org/10.3354/meps 11353

Carvalho F.M., Castello J.P. 2013. Argentine anchovy (Engraulis anchoita) stock identification and incipient exploitation in southern Brazil. Lat. Am. Aquat. Res. 41: 820-827.

https://doi.org/10.3856/vol41-issue5-fulltext-2

Castellón A., Font J., García E. 1990. The Liguro-Provençal-Catalan current (Northwestern Mediterranean) observed by Doppler profiling in the Balearic Sea. Sci. Mar. 54: 269-276.

Cendrero O., Abaunza P. 2001. Note on the diameter of otolith nucleus as a characteristic of the population groups of anchovy, Engraulis encrasicolus (Linnaeus, 1758), of the Cantabrian Sea and Galicia. Bol. Inst. Esp. Oceanogr. 17: 317-321.

Clarke K.R., Gorley R.N. 2006. PRIMER v6: User Manual/Tutorial. PRIMER-E, Plymouth.

Costalago D., Navarro J., Álvarez-Calleja I., et al. 2012. Ontogenetic and seasonal changes in the feeding habits and trophic levels of two small pelagic fish species. Mar. Ecol. Prog. Ser. 460: $169-181$. https://doi.org/10.3354/meps09751

Cury P., Bakun A., Crawford R.J.M., et al. 2000. Small pelagic in upwelling systems: patterns of interaction and structural changes in "wasp-waist" ecosystems. ICES J. Mar. Sci. 57: 603-618. https://doi.org/10.1006/jmsc.2000.0712

El-Geziry T.M., Bryden I.G. 2010. The circulation pattern in the Mediterranean Sea: issues for modeller consideration. J. Operat. Oceanogr. 3(2): 39-46. https://doi.org/10.1080/1755876X.2010.11020116

Fréon P., Cury P., Shannon L., et al. 2005. Sustainable exploitation of small pelagic fish stocks challenged by environmental and ecosystem changes: a review. Bull. Mar. Sci. 76: 385-462.

Froese R. 2006. Cube law, condition factor and weight-length relationship: history, meta-analysis and recommendations. J. Appl. Ichthyol. 22: 241-253. https://doi.org/10.1111/j.1439-0426.2006.00805.x

GFCM. 2007. Resolution GFCM/31/2007/2 on the establishment of Geographical Sub-Areas in the GFCM Area.

GFCM. 2014. Report of the Working Group on Stock Assessment of Small Pelagic species (WGSASP). Bar, Montenegro, 28 January - 1 February 2014. Tech. rep. FAO. 52 pp.

GFCM. 2015. Report of the Working Group on Stock Assessment of Small Pelagic species (WGSASP). Rome, Italy, 23 November - 28 November 2015. Tech. rep. FAO. 82 pp.

Giráldez A., Abad R. 1995. Aspects on the reproductive biology of the western Mediterranean anchovy from coast of Malaga. Sci. Mar. 59: 15-23.

Green A.J. 2001. Mass/length residuals: measures of body condition or generators of spurious results. Ecology 82: 1473-1483. https://doi.org/10.1890/0012-9658(2001)082[1473:MLRMOB ]2.0.CO;2

Guerra-Sierra A., Sánchez-Lizaso J.L. 1998. Fundamentos de Explotación de Recursos Vivos Marinos. Ed. Acribia. Zaragoza, Spain. 249 pp.

Hernández C., Villamor B., Barrado J., et al. 2013. Age determination in European anchovy (Engraulis encrasicolus L.) otoliths in the Bay of Biscay (NE Atlantic). WD to the Workshop on Micro increment daily growth in European Anchovy and Sardine (WKMIAS). ICES 21 - 25 October 2013 Mazara del Vallo, Italy.

ICES. 2008. Report of the Workshop on Small Pelagics (Sardina pilchardus, Engraulis encrasicolus) maturity stages (WKSPMAT), 10-14 November 2008, ICES CM 2008/ACOM:40, Mazara del Vallo, Italy. $82 \mathrm{pp}$.

ICES. 2009. Report of the Workshop on Age reading of European anchovy (WKARA), 9-13 November 2009, ICES CM 2009/ ACOM: 43. Sicily, Italy, $122 \mathrm{pp}$.

ICES. 2013. Workshop on micro increment daily growth in European Anchovy and Sardine (WKMIAS), 21-25 October 2013, ICES CM 2013/ACOM. 51. Mazara del Vallo, Sicily. 153 pp.

Jansen T., Campbell A., Brunel T., et al. 2013. Spatial Segregation within the Spawning Migration of North Eastern Atlantic Mackerel (Scomber scombrus) as Indicated by Juvenile Growth Patterns. PLoS ONE 8: e58114. https://doi.org/10.1371/journal.pone.0058114

Jemaa S., Bacha M., Khalaf G., et al. 2015. Evidence for population complexity of the European anchovy (Engraulis encrasicolus) along its distributional range. Fish. Res. 168: 109-116. https://doi.org/10.1016/j.fishres.2015.04.004

Kline L. 1996. Fisheries research under fire: more than just a money issue. Fisheries 21: 4-5.

Ladich F., Schulz-Mirbach T. 2016. Diversity in fish auditory systems: one of the riddles of sensory biology. Front. Ecol. Evol. 4: $1-26$. 
https://doi.org/10.3389/fevo.2016.00028

Lazzari P., Solidoro C., Ibello V., et al. 2012. Seasonal and inter-annual variability of plankton chlorophyll and primary production in the Mediterranean Sea: a modelling approach. Biogeosci. Discuss. 8: 5379-5422.

https://doi.org/10.5194/bgd-8-5379-2011

Le Cren E.D. 1951. The length-weight relationship and seasonal cycle in gonad weight and condition in the perch (Perca fluviatilis). J. Anim. Ecol. 20: 201-219. https://doi.org/10.2307/1540

Lleonart J., Maynou F. 2003. Fish stocks assessments in the Mediterranean: state of the art. Sci. Mar. 67(Suppl. 1): 37-49.

McClatchie S., Thorne R.E., Grimes P., et al. 2000. Ground truth and target identification for fisheries acoustics. Fish. Res. 47: 173-191. https://doi.org/10.1016/S0165-7836(00)00168-5

Mercado J.M., Cortés D., Gómez F., et al. 2013. A method based on satellite imagery to evaluate the eutrophication at MSFD scale in the Alboran Sea. Rapport du CIESM, Vol. 40.

Morales-Nin B., Pertierra J.P. 1990. Growth rates of the anchovy Engraulis encrasicolus and the sardine Sardina pilchardus in the Northwestern Mediterranean Sea. Mar. Biol. 107: 349-356. https://doi.org/10.1007/BF01319836

Palomera I. 1992. Spawning of anchovy Engraulis encrasicolus in the Northwestern Mediterranean relative to hydrographic features in the region. Mar. Ecol. Prog. Ser. 79: 215-223. https://doi.org/10.3354/meps079215

Palomera I., Sabatés A. 1990. Co-occurrence of Engraulis encrasicolus eggs and larvae in the North-Western Mediterranean. Sci. Mar. 54: 61-67.

Panfili J., de Pontual H., Troadec H., et al. 2002. Manual of Fish Sclerochronology. Ifremer-IRD. Brest, France. 499 pp.

Pannella G. 1971. Fish otoliths: daily growth layers and periodical patterns. Science 173: 1124-1127. https://doi.org/10.1126/science.173.4002.1124

Pennington M., Stromme T. 1998. Surveys as a research tool for managing dynamic stocks. Fish. Res. 37: 97-106. https://doi.org/10.1016/S0165-7836(98)00129-5

Pertierra J.P. 1987. Crecimiento del boquerón (Engraulis encrasicolus, L. 1758) (Pisces, Engraulidae) de la costa catalana (Mediterráneo noroccidental). Inv. Pesq. 51: 263-275.

Pinot J.M., López-Jurado J.L., Riera M. 2002. The Canales experiment (1996-1998). Interannual, seasonal and mesoscale variability of the circulation in the Balearic Channels. Prog. Oceanogr. 55: 335-370. https://doi.org/10.1016/S0079-6611(02)00139-8

Pla C., Tudela S., García-Marín J.L. 1996. Diversity and population structure of the European anchovy in the Mediterranean Sea. Sci. Mar. 60(Suppl. 2): 285-286.

Quetglas A., Guijarro B., Ordines F., et al. 2012. Stock boundaries for fisheries assessment and management in the Mediterranean: the Balearic Islands as a case study. Sci. Mar. 76: 17-28. https://doi.org/10.3989/scimar.2012.76n1017

Quintanilla J.M., Laiz-Carrión R., Uriarte A., et al. 2015. Influence of trophic pathways on daily growth patterns of western Mediterranean anchovy Engraulis encrasicolus larvae. Mar. Ecol. Prog. Ser. 531: 263-275. https://doi.org/10.3354/meps 11312

R Development Core Team. 2015. R: A language and environment for statistical computing. R Foundation for Statistical Comput- ing, Vienna, Austria.

https://www.R-project.org/

Rodriguez Mendoza R.P. 2006. Otoliths and their applications in fishery science. Ribarstvo 64: 89-102.

Salat J. 1996. Review of hydrographic environmental factors that may influence anchovy habitats in North Western Mediterranean. Sci. Mar. 60(Suppl. 2): 21-32.

Salgado L., Lorenzo M.N. 2014. Variabilidad de la clorofila a en las aguas costeras de la península Ibérica entre 1998 y 2007 usando datos de SeaWiFS. A.C.T. 5: 86-99.

Sanz N., García-Marín J.L., Viñas J., et al. 2008. Spawning groups of European anchovy:population structure and management implications. ICES J. Mar. Sci. 65: 1635-1644. https://doi.org/10.1093/icesjms/fsn128

Secor D.H., Dean J.M., Laban E.H. 1992. Otolith removal and preparation for microstructural examination. Canadian Spec. Publ. Fish. Aquat. Sci. 117: 19-57.

Shaltout M., Omstedt A. 2014. Recent sea surface temperature trends and future scenarios for the Mediterranean Sea. Oceanologia 56: 411-443. https://doi.org/10.5697/oc.56-3.411

Simmonds E.J., Williamson N.J., Gerlotto F., et al. 1992. Acoustic survey design and analysis procedures: a comprehensive review of current practice. ICES Co-operative Res. Rep. 187: 1-127.

Siokou-Frangou I., Christaki U., Mazzocchi M.G., et al. 2010. Plankton in the open Mediterranean Sea: a review. Biogeosciences 7: 1543-1586. https://doi.org/10.5194/bg-7-1543-2010

Uriarte A., Pouzet P., Villamor B. 1996. Bay of Biscay and Ibero Atlantic anchovy populations and their fisheries. Sci. Mar. 60(Suppl. 2): 237-255.

Uriarte A., Rico I., Villamor B., et al. 2016. Validation of age determination using otoliths of the European anchovy (Engraulis encrasicolus L.) in the Bay of Biscay. Mar. Freshwater Res. 67: 951-966 https://doi.org/10.1071/MF15092

Van Beveren E., Bonhommeau S., Fromentin J.M., et al. 2014. Rapid changes in growth, condition, size and age of small pelagic fish in the Mediterranean. Mar. Biol. 161: 1809-1822. https://doi.org/10.1007/s00227-014-2463-1

Vasilakopoulos P., Maravelias C.D., Tserpes G. 2014. The alarming decline of Mediterranean fish stocks. Curr. Biol. 24: 1643-1648. https://doi.org/10.1016/j.cub.2014.05.070

Villamor B., Navarro M.R., Hernández C., et al. 2014. Age determination procedures on small pelagic species in Spanish Institute of Oceanography (IEO). Int. Doc. IEO, $40 \mathrm{pp}$.

Viñas J., Sanz N., Peñarrubia L., et al. 2013. Genetic population structure of European anchovy in the Mediterranean Sea and the Northeast Atlantic Ocean using sequence analysis of the mitochondrial DNA control region. ICES J. Mar. Sci. 711: 391-397.

Zarraonaindia I., Iriondo M., Albaina A., et al. 2012. Multiple SNP Markers Reveal Fine-Scale Population and Deep Phylogeographic Structure in European Anchovy (Engraulis encrasicolus L.). PLoS ONE 7: e42201. https://doi.org/10.1371/journal.pone.0042201

Zengin M., Saygin S., Polat N. 2015. Otolith Shape Analyses and Dimensions of the Anchovy Engraulis encrasicolus L. in the Black and Marmara Seas. Sains Malays. 44: 657-662. https://doi.org/10.17576/jsm-2015-4405-03 